\title{
Major Ampullate Spider Silk with Indistinguishable Spidroin Dope Conformations Leads to Different Fiber Molecular Structures
}

\author{
Justine Dionne, Thierry Lefèvre * and Michèle Auger \\ Regroupement québécois de Recherche sur la Fonction, l'Ingénierie et les Applications des Protéines (PROTEO), \\ Centre de Recherche sur les Matériaux Avancés (CERMA), Centre Québécois sur les Matériaux \\ Fonctionnels (CQMF), Département de Chimie, Université Laval, Pavillon Alexandre-Vachon, Ville de Québec, \\ QC G1V 0A6, Canada; justine.dionne.1@ulaval.ca (J.D.); michele.auger@chm.ulaval.ca (M.A.) \\ * Correspondence: thierry.lefevre@chm.ulaval.ca; Tel.: +1-418-656-2131 (ext. 6460); Fax: +1-418-656-7916
}

Academic Editors: John G. Hardy and Chris Holland

Received: 21 July 2016; Accepted: 15 August 2016; Published: 18 August 2016

\begin{abstract}
To plentifully benefit from its properties (mechanical, optical, biological) and its potential to manufacture green materials, the structure of spider silk has to be known accurately. To this aim, the major ampullate (MA) silk of Araneus diadematus (AD) and Nephila clavipes (NC) has been compared quantitatively in the liquid and fiber states using Raman spectromicroscopy. The data show that the spidroin conformations of the two dopes are indistinguishable despite their specific amino acid composition. This result suggests that GlyGlyX and GlyProGlyXX amino acid motifs ( $X=$ Leu, Glu, Tyr, Ser, etc.) are conformationally equivalent due to the chain flexibility in the aqueous environment. Species-related sequence specificity is expressed more extensively in the fiber: the $\beta$-sheet content is lower and width of the orientation distribution of the carbonyl groups is broader for $A D\left(29 \%\right.$ and $58^{\circ}$, respectively) as compared to $N C\left(37 \%\right.$ and $51^{\circ}$, respectively). $\beta$-Sheet content values are close to the proportion of polyalanine segments, suggesting that $\beta$-sheet formation is mainly dictated by the spidroin sequence. The extent of molecular alignment seems to be related to the presence of proline (Pro) that may decrease conformational flexibility and inhibit chain extension and alignment upon drawing. It appears that besides the presence of Pro, secondary structure and molecular orientation contribute to the different mechanical properties of MA threads.
\end{abstract}

Keywords: Raman spectromicroscopy; spider silk fibers; spinning dope; silk protein structure; molecular orientation; orientation distribution function

\section{Introduction}

Spider silk proteins (spidroins) represent the basic constituent of a range of natural filaments that are used to fulfill specific biological functions. Relying on its biocompatibility and remarkable mechanical properties, this raw material may become a promising resource for materials science. It may lead in the future to diverse and useful applications in various fields including biomedicine, optoelectronics, high-tech threads or textiles, particularly in a context where society's sustainability requires, among other societal progresses, the development of green and durable technologies [1-5]. It is then desirable to reproduce natural silk in the laboratory and at industrial scale, or to produce silk-inspired materials with tailored characteristics. To achieve this goal, a deep understanding of the structure and formation of silk is necessary.

Silk threads are produced by spiders in specialized glands located in their abdomen. The archetype of silk is the dragline which is produced by the major ampullate (MA) gland and is thus termed MA silk. Its basic structural organization can be described by stiff crystalline nanodomains constituted by highly oriented polypeptide chain segments folded into $\beta$-sheets and distributed in an amorphous soft matrix 
composed of protein chains that adopt less oriented and more disordered secondary structures [6-8]. This semicrystalline architecture governs silk mechanical properties as it is influenced by the level of molecular orientation, the fraction of the crystalline phase, the limited size of the $\beta$-sheet nanocrystals, and by the hydrogen bonded network of the amorphous chains [9-14], among other factors.

The final material results from the molecular transformations of spidroins and their assembly during the course of the spinning process which is in turn generated by the mechanical constraints imposed by the spider. The sequence of the spidroin amino acid building blocks is segmented into successive motifs that undergo conformational and orientational changes during silk formation. MA spidroins include polyalanine (poly-Ala) segments which form the $\beta$-sheets $[15,16]$ and glycine-rich segments GlyGlyX and GlyProGlyXX (GGX and GPGXX) (with X = Leu, Glu, Tyr, Ser, etc.) which constitute the disordered phase ( $3_{1}$-helices, turns) [17-20]. The MA fiber of orb-weaving spiders is actually made of two analogous spidroins which vary in proportion and slightly differ in sequence depending on the species, particularly in terms of proline (Pro) content. For example, in the case of Nephila clavipes (NC), the main protein (MaSp1, 80\% mole) is Pro-free while MaSp2 is marked by the presence of Pro under the form of GPGXX motifs [21,22]. In the case of Araneus diadematus (AD), the two proteins (termed ADF3 and ADF4) [23] are both rich in Pro, leading to a higher global Pro content (16\%, while NC contains only $3.5 \%)[24,25]$.

Major advances have been made to understand how spidroin primary structure (repetitive segment [26-29], non-repetitive $\mathrm{N}$ - and C-terminal regions [30,31]), spinning process (rheology [32,33], anatomy and ultrastructure of the gland $[34,35]$ as well as physicochemical conditions of the lumen [36-38]) contribute to the formation of the final structure and to its properties. Among other factors, the role of Pro on the mechanical behavior of MA silk has been emphasized, especially since the discovery that the Pro content is positively correlated with the extent of supercontraction [13,39], a phenomenon by which silk fibers shrink longitudinally and swell radially upon exposure to water. The influence of Pro residues has been attributed to an increase in water plasticization due to a disordering effect on the polypeptide chains in the amorphous phase [13,39-42]. The improvement in the mechanics of MA silk upon evolution (extensibility, toughness) has been correlated with the appearance of the Pro-rich MaSp2 spidroins in the Orbiculariae clade [43].

Silk thread structure is determined by the protein sequence characteristics and spinning process (Figure 1). The importance of both factors has been emphasized [26,39,44-49]. Whereas it may be inferred that silk structure is mainly "encoded" in the sequence (such that the spinning process may appear relatively unimportant), the MA gland environment and the way molecular transformations are induced are essential to lead to the appropriate fiber structure. Both factors are actually interconnected: the spinning process converts the spidroins conformation occurring in the sac of the MA gland into the highly organized structure of the fiber. However, the initial and final states as well as the response of the polypeptide chain to mechanical and physicochemical stimuli depend intimately on the sequence. The initial conformation may also by itself influence the molecular transformations that lead to the final structure. Overall, the relative contributions of the composition and architecture of the spidroins sequence on one hand and the spinning process on the other hand remains unclear.

To better understand the initial-to-final structure transition and the role of the sequence and spinning process, structural differences that may exist between MA silks from different spiders have to be evaluated in both the liquid (dope) and solid (fiber) states. The comparison of silks reeled in the same conditions and at the same speed may minimize the effect of the spinning process, thus potentially evidencing small structural differences due to the specificities of the spidroin's primary structure. This is particularly relevant since the sequence, in particular the Pro content, can influence the conformation of the spidroins both in the dope and in the fiber.

Although tensile properties of MA silk of numerous spider species have been extensively investigated [13,39,50-57], researches devoted to comparisons of their structures are scarce. Even for the two most widely investigated spiders ( $A D$ and $N C$ ), data are lacking, in particular regarding the level of molecular orientation. A lower birefringence of $A D$ with respect to $N C$ has however been 
measured [13] and a higher level of random coil conformation has been proposed for $A D$ from Raman spectromicroscopy [58]. A major advance has been made recently by a broad phylogenetic X-ray diffraction investigation of MA silk fibers [51]. Systematic data regarding the comparison of spidroin conformations in the MA dope of different species are inexistent.

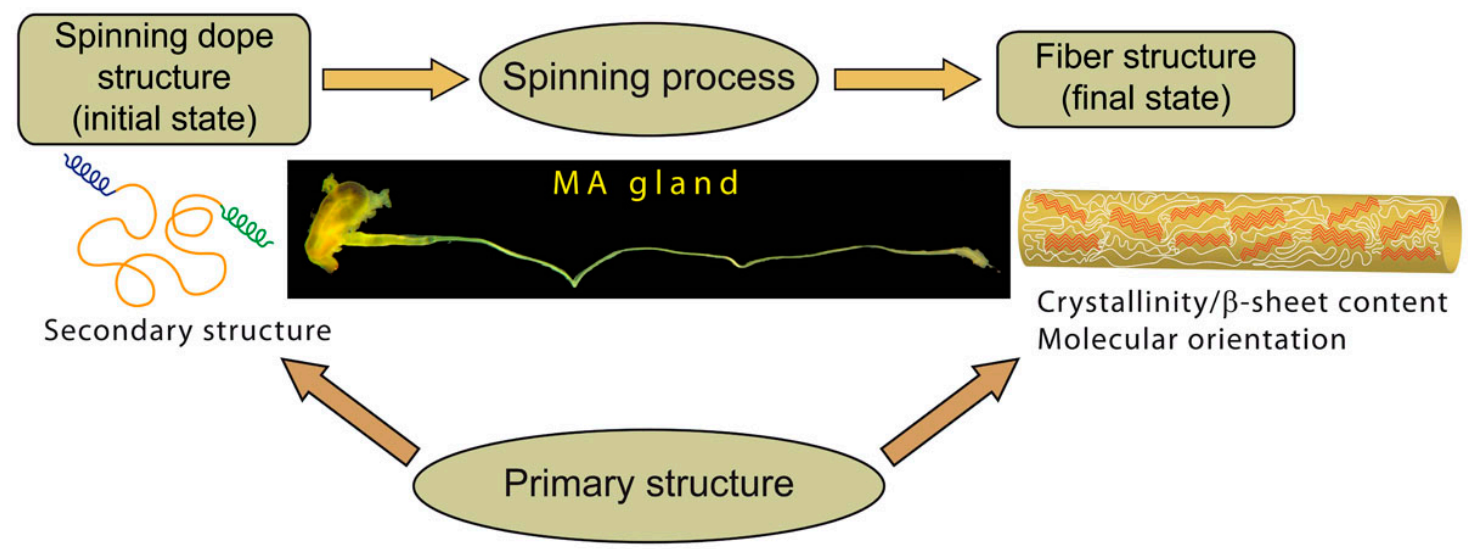

Figure 1. Schematics showing the relationships between the structure of major ampullate (MA) spidroins in the silk dope, the fiber structure, the spinning process and the primary structure. Silk formation corresponds to the transformation converting the spidroins in the dope (initial conformational state) into the silk fiber (final structural state). The spinning process (mechanical constraints applied, physicochemical environment) and primary structure (chemical composition) are the two factors that govern structural changes. On one hand, the spinning process triggers and induces conformational and orientational changes to the polypeptide chains. On the other hand, the response of spidroins and the final secondary structure they adopt are dictated by the sequence.

The aim of this study is thus to compare quantitatively the molecular structure of $N C$ and $A D M A$ silk dopes and fibers. Raman spectromicroscopy has been used to investigate single monofilament and gland content and to determine the orientation level and secondary structure content. The present data suggest that besides the role of Pro residues, other molecular structural characteristics such as $\beta$-sheet content and molecular orientation have to be considered to exhaustively describe species-related differences in the mechanical properties of the MA spider silks. The sequence specificities also appear essential for the formation of the fiber structure.

\section{Results}

\subsection{Spidroins Conformation in the Major Ampullate (MA) Dope}

Raman spectra of the native silk dope of the NC and AD MA glands are shown in Figure 2. The normalized Raman intensity displays unique information about the chemical constituents of the spinning dopes. Since the silk dope is isotropic, Raman intensity is only influenced by the chemical composition and conformation of the samples. In other words, molecular orientation does not affect the Raman spectra. Some bands are conformation-sensitive whereas others are representative of the amino acid residues.

Bands representative of the secondary structure are mainly due to the peptide bonds, especially regarding the amide modes. The shape and position of the amide I bands $\left(1658 \mathrm{~cm}^{-1}\right)$ are superimposable for the two spider species as revealed by the inset scheme in Figure 2. This result indicates that the conformation of the spidroins is identical for NC and $A D$. As discussed elsewhere [16,59], these amide I bands reveal that the silk dope is essentially disordered with a small contribution from $\alpha$-helix [60]. The amide III band is also very similar for both species, with two components at 1244 and $1260 \mathrm{~cm}^{-1}$ which are characteristic of disordered structure. The skeletal $\mathrm{C}_{\alpha}-\mathrm{C}_{\beta}$ stretching band appears at $1103 \mathrm{~cm}^{-1}$ and supports the previous random coil assignment. 
The spectra also exhibit a peak at $525 \mathrm{~cm}^{-1}$ due to poly-Ala with an $\alpha$-helical conformation. The lower intensity for $A D$ indicates lower percentage of poly-Ala in the sequence.

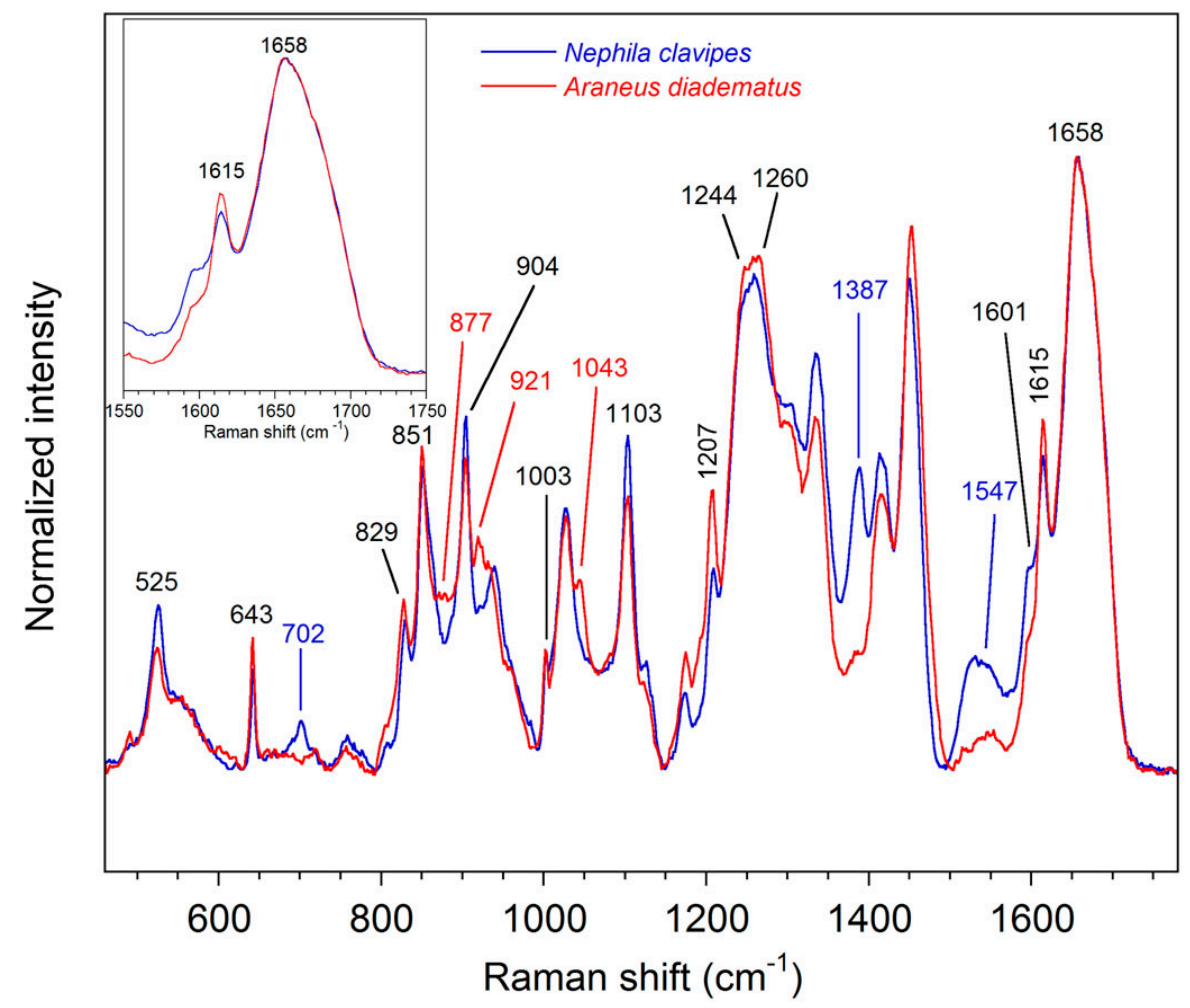

Figure 2. Raman spectra of the spinning dope contained in the sac of the Nephila clavipes (NC) and Araneus diadematus $(A D)$ MA glands.

Bands due to the amino acid side-chains allow discrimination between different silks. In particular, Pro bands at 877,921 , and $1043 \mathrm{~cm}^{-1}$ only appear in the spectrum of the $A D$ dope. This was expected since, as previously mentioned, the MA spidroins of $A D$ contain more Pro compared to NC [24,25]. Peaks due to tyrosine (Tyr) at $643,829,851$, and $1615 \mathrm{~cm}^{-1}$ and to poly-Ala at $904 \mathrm{~cm}^{-1}$ are found in both spectra of liquid MA silk although that those related to Tyr are more intense for $A D$. Bands due to phenylalanine (Phe) residues arise at 1003 and $1601 \mathrm{~cm}^{-1}$ and the peak at $1207 \mathrm{~cm}^{-1}$ is characteristic of Phe and Tyr. A non-protein constituent previously identified as an isoquinoline compound [61] arises at 702, 1387, and $1547 \mathrm{~cm}^{-1}$ in the spectrum of NC [62].

\subsection{Molecular Structure of the MA Fibers}

\subsubsection{Qualitative Analysis}

Figure 3 shows the polarized $\mathrm{I}_{X X}$ and $\mathrm{I}_{Z Z}$ spectra of the $N C$ and $A D$ MA threads. The complete series of polarized spectra are given in Figure S1. Unlike the dopes, silk fibers display anisotropy. Raman intensity thus depends not only on the conformation but also on molecular orientation. Regarding amino acid side-chains, the peaks due to Tyr at $641,827,851$, and $1615 \mathrm{~cm}^{-1}$, to Phe at 1002 and $1602 \mathrm{~cm}^{-1}$, to Phe/Tyr at $1209 \mathrm{~cm}^{-1}$ and to poly-Ala at $903 \mathrm{~cm}^{-1}$ are still prominent for $A D$ and NC. Consistently with the spectra of the liquid silk, the Pro bands at 877,919 , and $1041 \mathrm{~cm}^{-1}$ are only observed for $A D$. Peaks associated with isoquinoline in $N C$ come out at 700 and $1550 \mathrm{~cm}^{-1}$. The band previously found at $1387 \mathrm{~cm}^{-1}$ overlaps with another vibrational mode due to the chain backbone at around $1396 \mathrm{~cm}^{-1}$ [63]. 


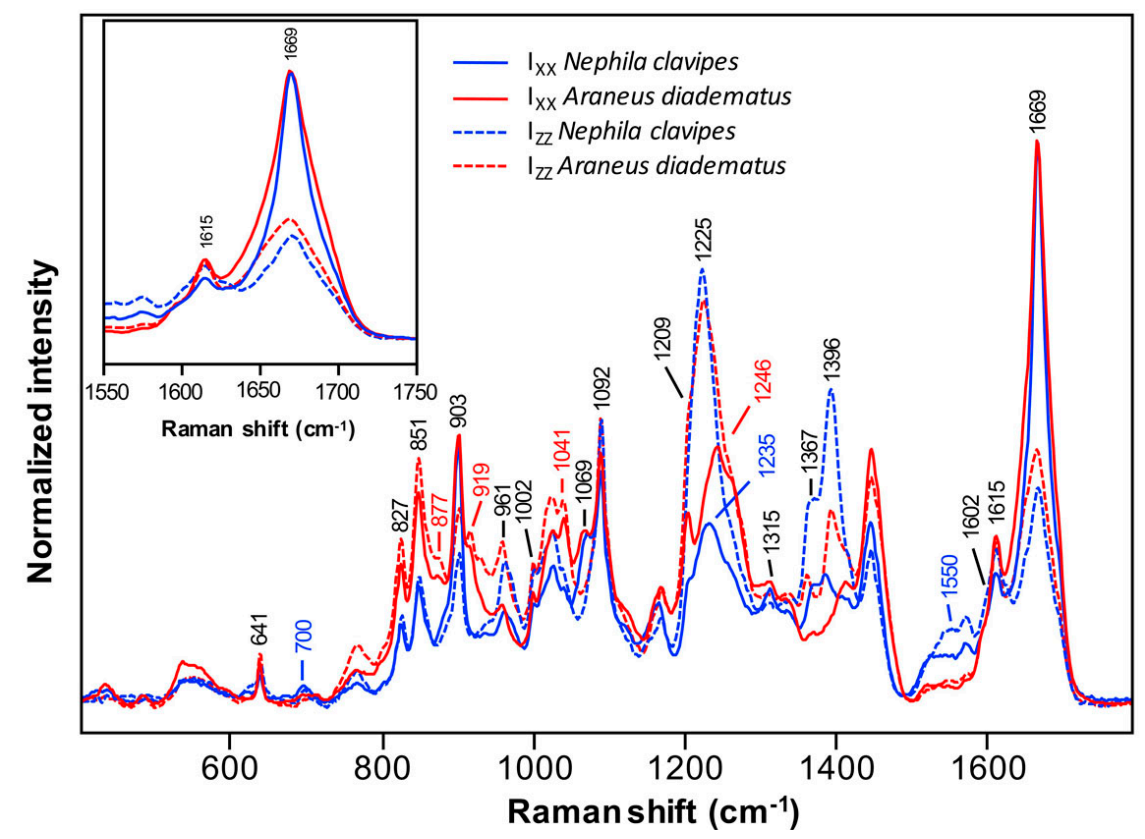

Figure 3. Polarized $\mathrm{I}_{X X}$ and $\mathrm{I}_{Z Z}$ Raman spectra of Nephila clavipes and Araneus diadematus MA silk fibers. Spectra are normalized so that the $I_{X X}$ peak maximum is equal in the amide I region. They represent the mean spectra calculated over 12-14 series of measurements.

As confirmed by the positions of the $\mathrm{I}_{X X}$ amide I band at $1669 \mathrm{~cm}^{-1}$ and the amide III bands at 1225 and $1246 \mathrm{~cm}^{-1}$, both fibers exhibit a predominance of $\beta$-sheets. Other conformation-sensitive bands at $961,1315,1367$, and $1396 \mathrm{~cm}^{-1}$ and skeletal $C_{\alpha}-C_{\beta}$ stretching at 1069 and $1092 \mathrm{~cm}^{-1}$ confirm that the $\beta$-sheet conformation is preponderant for the two spiders. The bands at 1367 and $1396 \mathrm{~cm}^{-1}$ are more intense in the IZZ spectrum of $N C$ compared to $A D$, which suggests that $N C$ MA silk contains more $\beta$-sheets than $A D$. However, a component of the isoquinoline contaminant described earlier contributes to the band at $1396 \mathrm{~cm}^{-1}$. Furthermore, the IXX amide III band of NC is less intense and is located at $1235 \mathrm{~cm}^{-1}$ rather than at $1246 \mathrm{~cm}^{-1}$ for $A D$. This difference is explained below.

The variations of band intensities with polarization indicate that the proteins in MA filaments exhibit a preferential orientation. The $\beta$-sheets of MA fiber are known to be oriented along the fiber axis [64,65]. Consequently, the carbonyl groups of the peptide bonds, which are principally responsible for the amide I signal, are mainly perpendicular to the fiber axis (Figure S2). A higher intensity of the amide $I$ band in the $I_{X X}$ spectrum is then expected over the $I_{Z Z}$. For comparison purposes, the $I_{X X}$ amide I bands of all series of spectra have been normalized to unity. Consequently, the weaker the $\mathrm{I}_{\mathrm{ZZ}}$ amide I band, the higher the orientation of the fiber. Conversely, a stronger IZZ amide III band, or a weaker IXX amide III band, means a higher orientation of the chains since the amide III band is mostly due to the $\mathrm{C}-\mathrm{N}$ stretch of the peptide bond which is oriented along the fiber axis in $\beta$-sheets [66].

Figure 3 shows that the IZZ amide I band of NC is weaker and its IZZ amide III band is more intense as compared to $A D$ (its I $\mathrm{XX}$ amide III band is also weaker). Those observations suggest that the $N C$ MA spidroins are more oriented than those of $A D$. Furthermore, the inset illustration in Figure 3 reveals that the amide I band of $A D$ is broader compared to NC. This observation indicates that the $\beta$-sheets of the $A D$ fiber are less oriented and/or less abundant than for NC.

\subsubsection{Secondary Structure Content}

Figure 4 presents the orientation-insensitive spectra of $N C$ and $A D$ MA fibers in the amide I region calculated from the average polarized spectra. The Raman intensity of these spectra is only representative of the abundance of spidroin conformational elements, so that they can be used to evaluate the amount of secondary structures. Since the peak maximum of the amide I band at $1669 \mathrm{~cm}^{-1}$ 
is higher for $N C$ than for $A D$, it appears that the NC MA silk contains more $\beta$-sheets. Alternatively, the spectrum of $A D$ is broader compared to $N C$, especially at around $1645 \mathrm{~cm}^{-1}$, an observation that suggests that disordered structures are more abundant for the $A D$ silk.

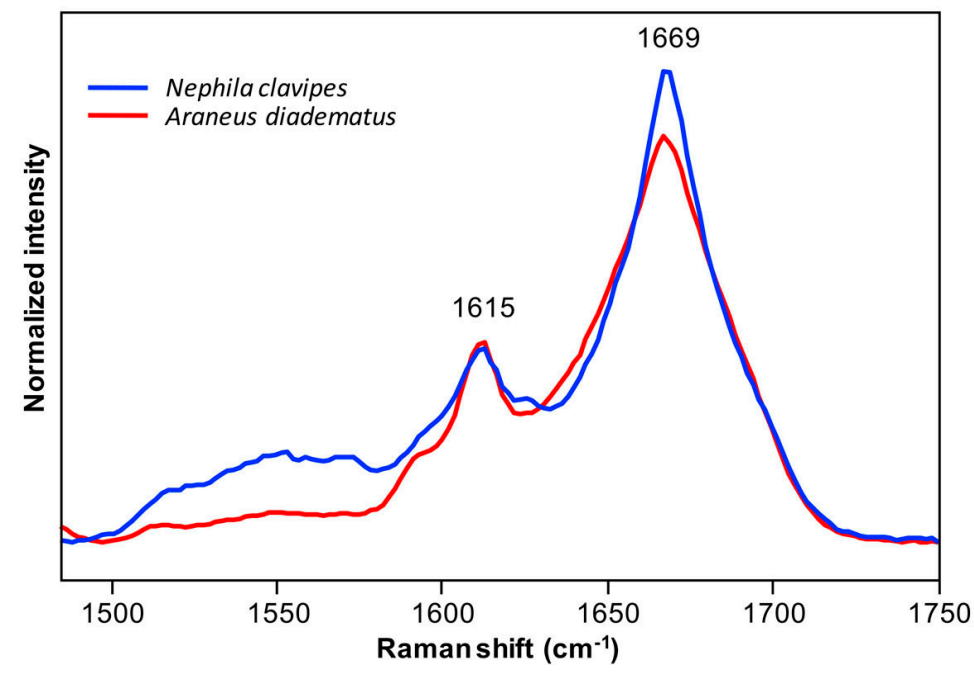

Figure 4. Orientation-insensitive spectra in the amide I region calculated from the average polarized Raman spectra of Nephila clavipes and Araneus diadematus fibers shown in Figure 3 and Figure S1. The spectra are normalized with respect to the total area of the amide I band.

The percentage of each secondary structure that contributes to the amide I band has been further estimated by curve-fitting (Figure 5). Consistently with the above qualitative analysis, the $\beta$-sheets are the predominant conformation in both MA fibers, the $\beta$-sheets being more prevalent in NC $(37 \%)$ than in $A D(29 \%)$ silk. The $A D$ filament contains more disordered structures which is in agreement with previous data [58]. A slight difference in the amount of $\beta$-turns at $1682 \mathrm{~cm}^{-1}$ is also found between the $A D(23 \%)$ and NC (19\%) threads. The approximate error on the band areas being $3 \%$, this distinction between the two species appears minor. Finally, NC and AD MA fibers have the same relative abundance of $3_{1}$-helices $(19 \%)$ and $\beta$-turns at $1697 \mathrm{~cm}^{-1}(12 \%-15 \%)$.

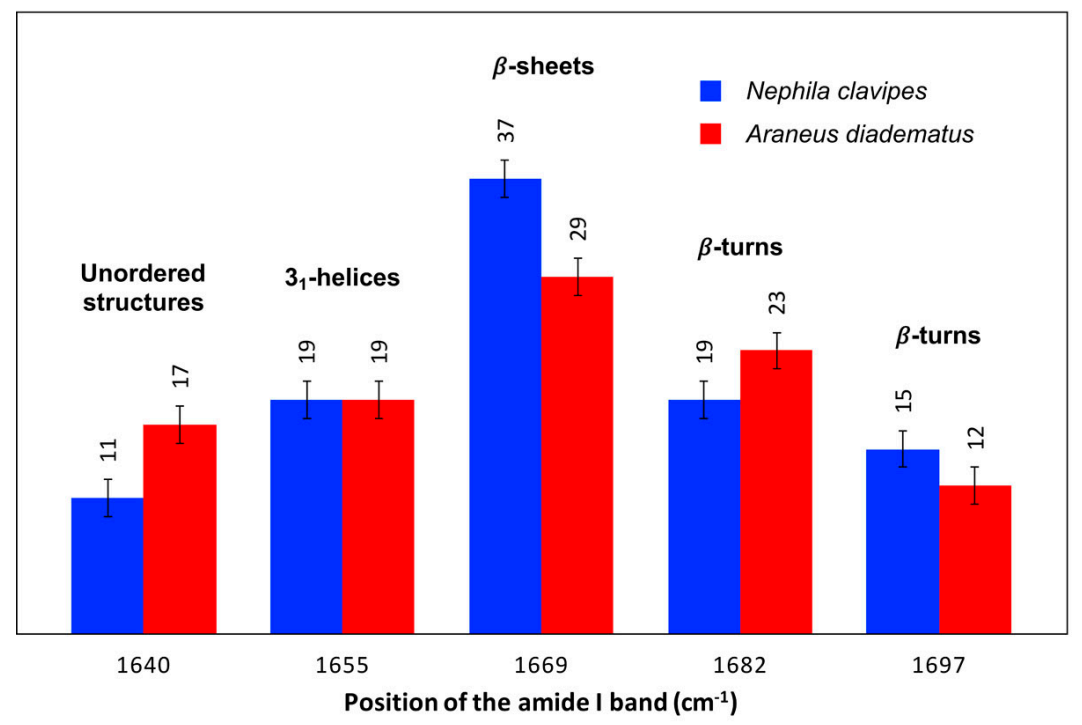

Figure 5. Relative band areas of the different amide I components of Nephila clavipes and Araneus diadematus fibers. The approximate error on the secondary structure content due to curve-fitting is $\pm 3 \%$ and is represented by the error bars on the figure. 


\subsubsection{Quantitative Orientation Analysis}

The molecular orientation of the $N C$ and $A D$ fibers was characterized using the polarized amide I vibration bands (mainly due to the $\mathrm{C}=\mathrm{O}$ stretching vibration). As this band is dominated by the $\beta$-sheet component, it is assumed that the orientation mainly reflects peptide bonds adopting a $\beta$-sheet conformation in the threads. The peak maximum of the amide I band was used to calculate the qualitative orientation parameter $R^{\prime}$ and the order parameters $P_{2}$ and $P_{4}$ from the intensity ratios $R_{1}$ and $R_{2}$. MA silk samples have a weaker $\mathrm{I}_{\mathrm{ZZ}}$ intensity in the amide I region, i.e., $R^{\prime}<1$ and $P_{2}<0$. A more negative value of $R^{\prime}=1-\left(I_{X X} / I_{Z Z}\right)$ indicates a higher degree of orientation of the $\beta$-sheets. Similarly, the more negative the $P_{2}$ value, the higher the molecular orientation.

The parameter $R^{\prime}$ as well as $P_{2}$ and $P_{4}$ for $A D$ and NC threads are presented in Table 1. $R^{\prime}$ values of -1.63 and -1.24 were found for $N C$ and $A D$ fibers, respectively, which confirm that the $N C$ silk is more oriented than $A D$. This qualitative result is confirmed by the quantitative $P_{2}$ and $P_{4}$ values calculated with the DC (depolarization constant) method (see the Experimental section). The $P_{2}$ values are negative due to the fact that the carbonyl groups are mainly perpendicular to the fiber axis. With the DC method, the $P_{2}$ value of the MA silk of $N C$ is lower (more negative) than for $A D$ indicating that NC spidroins are more oriented than $A D$ ones. The most probable distribution functions $N_{\mathrm{mp}}(\theta)$ estimated from the order parameters and the information theory is shown in Figure 6. The full width at half maximum (FWHM) is $57^{\circ}$ for $N C$ and $75^{\circ}$ for $A D$. The distribution of orientation is thus narrower for $N C$ than for $A D$, showing quantitatively that the level of orientation of MA silk is higher for NC. The maximum of the function appears at $90^{\circ}$ which is consistent with a perpendicular orientation of the structural units (carbonyl groups) for both species.

Table 1. Qualitative parameter $R^{\prime}=1-\left(I_{X X} / I_{Z Z}\right)$ and order parameters $P_{2}$ and $P_{4}$ of Nephila clavipes and Araneus diadematus major ampullate (MA) silk fibers as estimated from the polarized amide I bands and evaluated according to the depolarization constant (DC) and most probable distribution (MPD) methods.

\begin{tabular}{cccccc}
\hline \multirow{2}{*}{ Species } & \multirow{2}{*}{$\boldsymbol{R}^{*}$} & \multicolumn{2}{c}{$\boldsymbol{P}_{\mathbf{2}}{ }^{*}$} & \multicolumn{2}{c}{$\boldsymbol{P}_{\boldsymbol{4}}{ }^{*}$} \\
\cline { 3 - 6 } & & DC Method & MPD Method & DC Method & MPD Method \\
\hline N. clavipes & $-1.63 \pm 0.008$ & $-0.306 \pm 0.005$ & $-0.307 \pm 0.005$ & $0.075 \pm 0.005$ & $0.089 \pm 0.004$ \\
A. diadematus & $-1.24 \pm 0.008$ & $-0.256 \pm 0.007$ & $-0.258 \pm 0.006$ & $0.02 \pm 0.02$ & $0.059 \pm 0.003$ \\
\hline
\end{tabular}

* The order parameter values and the associated standard deviations were calculated from the mean intensity ratio values of each (three) fiber.

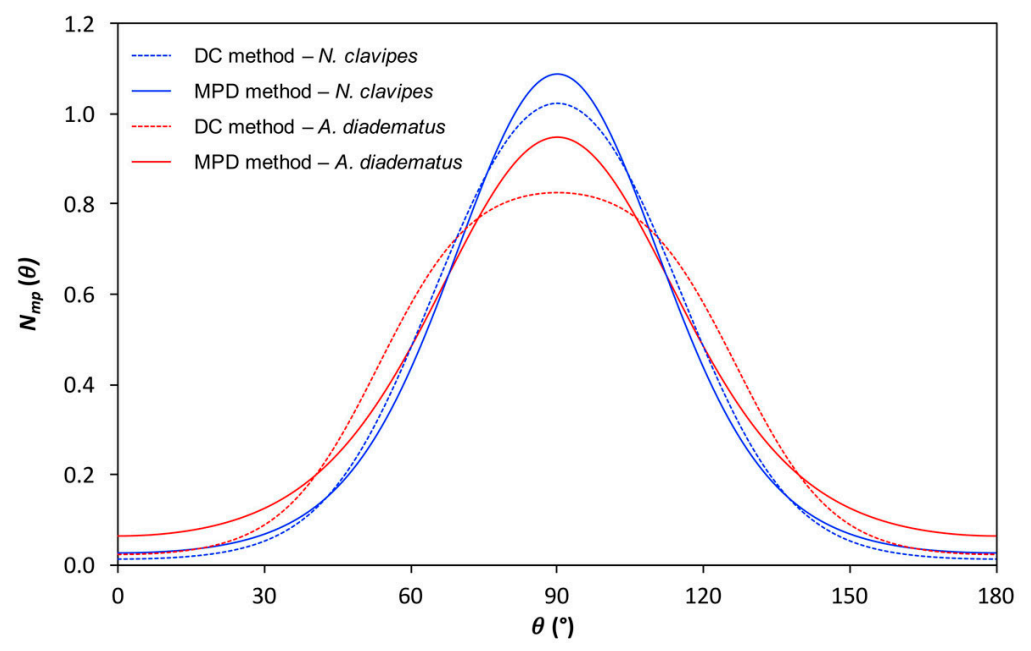

Figure 6. Most probable orientation distribution (MPD) functions, $N_{\mathrm{mp}}(\theta)$, of the carbonyl groups as determined from the order parameter values (Table 1) of Nephila clavipes and Araneus diadematus MA silk fibers according to the MPD and depolarization constant (DC) methods. 
As can be seen, the top of $N_{\mathrm{mp}}(\theta)$ of $A D$ is flattened, which actually seems not physically realistic. This flaw may be due to uncertainties on the intensity ratios and/or accuracy of the depolarization ratio. The values of order parameter $P_{4}$ is particularly sensitive to such variations and, as noticed previously [67], small differences in $P_{4}$ values can lead to significant differences in the orientation distributions. A second method, called the MPD (most probable distribution) method (see the Experimental section), assumes that the orientation distribution is Gaussian and has thus been tested to determine $P_{2}$ and $P_{4}$. The two methods give closely the same $P_{2}$ but different $P_{4}$ values (Table 1 ). The shape of $N_{\mathrm{mp}}(\theta)$ is not strongly affected by the calculation method for $N C$, but more important changes are observed for $A D$. As the orientation distribution functions of the two species are Gaussian with the MPD method, they are more appropriately compared. The FWHM calculated with the MPD method is $51^{\circ}$ for $N C$ and $58^{\circ}$ for $A D$ confirming that $N C$ spidroins are more oriented than those of $A D$ silk.

\subsection{Sequences Analysis}

The amino acid sequences of the spidroins forming the MA silk are presented in Figure 7. ADF3, ADF4, and MaSp2 all belong to spidroin-2 type [23] and exhibit the same motifs: blocks of $A_{n}$ and GA with a predominance of GPGXX motif. The spidroin-1 type MaSp1 is quite different with a prevalence of GGX motif, more $\mathrm{A}_{\mathrm{n}}$-GA regions and an absence of Pro. $A D$ and $N C$ also exhibit similar length of poly-Ala. Since AD MA silk seems to be composed of ADF3 and ADF4 proteins in a 3:2 ratio [23], the Pro content estimated from the sequence is about $15 \%$ whereas NC MA silk contains 3\% of Pro since MaSp1 accounts for $80 \%$ of the total protein content [13]. These Pro percentages are consistent with those determined by chemical methods [24,25].

\begin{tabular}{|c|c|c|c|}
\hline \multirow{6}{*}{$\begin{array}{l}\text { MaSp1 } \\
\text { GAGGAGAAAAAAGGA } \\
\text { AGAAAAAAAGGA } \\
\text { AGAAAAAAGGA } \\
\text { AGAAAAAAAGGA } \\
\text { AAAAAAGGA } \\
\text { AGAAAAAAGGA }\end{array}$} & \multirow{6}{*}{$\begin{array}{l}\text { GQGGYGGLGGQGAGQGGYGGLGGQGAGQG } \\
\text { GQGGGGGGGSOGAGRGGQG } \\
\text { GQGGYGGGSQGAGRGGLGGQG } \\
\text { GQGGYGGLGNQGAGRGGQG } \\
\text { GQGGGGGLSOGQGARGGLGGQG } \\
\text { GQGGGGGLGGQGAGQGGYGGLGSQGAGRGGL } \\
\text { GGQG }\end{array}$} & \multicolumn{2}{|l|}{ ADF3 } \\
\hline & & \multicolumn{2}{|r|}{ GPGQQGPYGPG } \\
\hline & & \multicolumn{2}{|c|}{ ASAAAAAA GGYGPGSGQQGPSQQGPGQQGPGGQGPYGPG } \\
\hline & & \multicolumn{2}{|c|}{ ASAAAAAA GGYGPGSGQQGPGGQGPYGPG } \\
\hline & & \multicolumn{2}{|c|}{ SSAAAAAA GGNGPGSGQQGAGQQGPG } \\
\hline & & \multicolumn{2}{|c|}{ ASAAAAAA GGYGPGSGQQGPGQQGPGGQGPYGPG } \\
\hline \multirow{2}{*}{$\begin{array}{l}\text { AGAAAAAAAGGA } \\
\text { AGASAAAAGGA }\end{array}$} & \multirow{3}{*}{$\begin{array}{l}\text { GQGGLGGQGAGQG } \\
\text { GQGGYGGLGSQGAGRGGEG } \\
\text { GQGGYGGLGGQGAGQGGYGGLGSQGAGRGGL } \\
\text { GGQG }\end{array}$} & \multicolumn{2}{|c|}{ ASAAAAAA GGYGPGSGQGPGQQGPGGQGPYGPG } \\
\hline & & \multicolumn{2}{|c|}{ ASAAAAAA GGYGPGSGQQGPGQQGPGQQGPGGOGPYGPG } \\
\hline AGAAAAAAGGA & & \multicolumn{2}{|c|}{ ASAAAAAA GGYGP GYGQQGPGQQGPGQQGPGGQGPYGPG } \\
\hline \multirow{2}{*}{$\begin{array}{l}\text { AGAAAAGGA } \\
\text { AGAAAAAAGGA } \\
\text { AGAVAAAAAGGA }\end{array}$} & \multirow{2}{*}{$\begin{array}{l}\text { GQGGLGGQGAGQG } \\
\text { GQGGYGGLGSQGAGRGGLGGQG } \\
\text { GOGGYGGLGSOGAGRGGQG }\end{array}$} & \multicolumn{2}{|c|}{ ASAASAAS GGYGPGSGQQGPGQQGPGGQGPYGPG } \\
\hline & & \multicolumn{2}{|c|}{ ASAAAAAA GGYGPGSGQQGP GQQGPGQQGPGQQGPGGQGPYGPG } \\
\hline \multirow{2}{*}{$\begin{array}{l}\text { AGAAAAAAGGA } \\
\text { AGAAAAAAAGGA } \\
\text { AAAAAGGA } \\
\text { AGAAAAAAVGA } \\
\text { AGAAAAAAGGA }\end{array}$} & $\begin{array}{l}\text { GQRGYGGLGN QGAGRGGLGGQG } \\
\text { GQGGYGGLGN QGAGRGGQG }\end{array}$ & ASAAAAAA GG & $\begin{array}{l}\text { GGYGPGSGQQGP GQQGP GQQGP GQQGP GQQGP GQQGP GQQ } \\
\text { GPGQOGPGQQGPGGQGAYGPG }\end{array}$ \\
\hline & $\begin{array}{l}\text { GQGGYGGLGSQGAGRGGQG } \\
\text { GQEGIRGQGAGQGGYGGLGSQGSGRGGLGGQG } \\
\text { GQGGLGGQGAGQG }\end{array}$ & ASAAAGAA $G$ & $\begin{array}{l}\text { GGYGP GSGQQGPGQQGPGQQGP GQQGP GQQQGP GQQGPGQQ } \\
\text { GPYGPG }\end{array}$ \\
\hline \multirow{3}{*}{$\begin{array}{l}\text { AGAAAAAAGG } \\
\text { AGAAAAAAGGA } \\
\text { AGAAAAGGA } \\
\text { ASAASAAAS }\end{array}$} & \multirow{2}{*}{$\begin{array}{l}\text { VROGGYGGLGSOGAGRGGOG } \\
\text { GQGGYGLGGGQGVRGGLGGQG } \\
\text { GOGGYGGYGSG }\end{array}$} & \multirow{2}{*}{$\begin{array}{l}\text { ASAAAAAA } G G \\
\text { AASAAVSV GG }\end{array}$} & GGYGP GSGQQGPGQQGPGQQGP GGQGPYGPG \\
\hline & & & GGYGPQS \\
\hline & & \multicolumn{2}{|c|}{ ADF4 } \\
\hline \multicolumn{2}{|l|}{$\begin{array}{l}\text { MaSp2 } \\
G A G A G A G\end{array}$} & \multicolumn{2}{|c|}{ GSSAAAAAAAA SGSGGYGPENQGPSGPVAYGPGGP } \\
\hline & \multirow{3}{*}{$\begin{array}{l}\text { RPGGYGPGQQGPGGYGPGQQ GPSGPG } \\
\text { GPGGYGPGQQGPGGYGPQQGPGRYGPGQQGP SGPG } \\
\text { GSGQQGPGYGPRQQGPGGYGQGQQGPSGPG }\end{array}$} & \multicolumn{2}{|c|}{ VSSAAAAAAA GSGPGGYGPENQGPSGPGGYGP G } \\
\hline \multirow{2}{*}{$\begin{array}{ll}\text { AAAAAA } & R P \\
\text { SAAAAAAAAAA } & \text { GP } \\
\text { SAAAAAA } & \text { GS }\end{array}$} & & SSAAAAAAAA & SGPGGYGPGSQGP SGP GGSGGYGP GSQGAS GPGGPG \\
\hline & & ASAAAAAAAAA & AAA SGPGGYGPGSQGPSGP GAYGPGGPG \\
\hline $\begin{array}{lll}\text { SAAAASAAASA } & \text { ES } \\
\text { PS }\end{array}$ & $\begin{array}{l}\text { ESGQQ,GP GGYGP GQQGP GGYGP GGYGP GGYGP GQQG } \\
\text { PSGPG }\end{array}$ & SSAAAAAAAA & GPGGYGPGSQGPSGP GVYGP GGPG \\
\hline SAAAAAAAAS & GPGQQGPGGYGPGQQGPGGYGPGQQGPSGPG & SSAAAAAAA & GSGPGGYGPENQGP SGP GGYGPGGSG \\
\hline SAAAAAAAAS & GPGQQGPGGYGPGQQGPGGYGPGQQGISGPG & SSAAAAAAAA & SGPGGYGPGSQ GP SGP GGSGGYGP GSQGGSGPG \\
\hline SAAAAAAA & $\begin{array}{l}\text { GPGQQGPGGYGPGQQGPSGPG } \\
\text { GPGGYGPGOOGPGGYGPGOOGPSGAG }\end{array}$ & ASAAAAAAAA & SGPGGYGPGSQ GP SGP GYQGPSGP \\
\hline $\begin{array}{l}\text { SAAAAAAAAA } \\
\text { SAAAAAAA }\end{array}$ & $\begin{array}{l}\text { GPGGYGPGQQGPGGYGPGQQGPSGAG } \\
\text { GPQQQGLGYYGPGQGPGGYGPGQQGP GGYGPG }\end{array}$ & & \\
\hline & & & \\
\hline $\begin{array}{l}\text { SASAAAAAAAA GF } \\
\text { SASAAAAAAAA GP }\end{array}$ & $\begin{array}{l}\text { GPGGYGPGQQGPGGYAPGQQG GPSGPG } \\
\text { GPGGYGPGQQGPGGYAPGQQGPSGPG }\end{array}$ & & \\
\hline SAAAAAAAAA & GPGGYGPAQQGPSGPGI & & \\
\hline AASAASA GP & GPGGYGPAQQGPAGYGPG & & \\
\hline $\begin{array}{l}\text { SAVAASAGAGSA GY } \\
\text { ASAAAS }\end{array}$ & & & \\
\hline
\end{tabular}

Figure 7. Amino acid sequences for the spidroins composing the MA gland silk of Araneus diadematus (ADF3 and ADF4) [23] and Nephila clavipes (MaSp1 and MaSp2) [21,22]. Single letter code for amino acids is used to simplify the analysis. The $A_{n}, G A, G G X$, and GPGXX motifs are inspired from those of Gatesy et al. [44] and are indicated in red, orange, blue, and green respectively, where $X$ represents a small subset of amino acids $(X=\mathrm{L}, \mathrm{Q}, \mathrm{T}, \mathrm{S}$, etc.). Amino acids that have undergone substitution in the motifs are colored in black and those that do not contribute to any motifs are colored in grey. 
The proportion of poly-Ala estimated from the sequence, including the GA motifs [18,20], is $34 \%$ for $N C$ and $23 \%$ for $A D$. This difference is consistent with the lower intensity of the poly-Ala band at $525 \mathrm{~cm}^{-1}$ for $A D$ silk dope. Assuming that the poly-Ala regions form the $\beta$-sheets $[15,17,68]$, there is a good agreement between the $\beta$-sheet content evaluated from the Raman and sequence analyses. There is a small discrepancy between both methods (Raman analysis gives higher values than the sequence analysis), but the amount of $\beta$-sheets seems to be roughly predictable from the poly-Ala content.

\section{Discussion}

\subsection{The Conformation of the Spidroins in the Dope Is Not Critical for the Fiber Structure}

The amino acid composition of the NC and $A D$ MA silks are similar but distinct, the former fiber being mainly composed of the Pro-deficient MaSp1, the latter being formed of two Pro-rich MaSp2-like spidroins. These different chemical compositions do not lead to distinctive conformation in the sac of the MA gland. This observation is consistent with the fact that recombinant MaSp1 and MaSp2 spidroins do not reveal conformational differences in solution by vibrational spectroscopy [69]. It may then be hypothesized that the sequence difference is not determinant for the initial spidroin conformation. Overall, vibrational bands of the backbone show that for both species the secondary structure is typical of disordered proteins, with a minor contribution of $\alpha$-helix.

Contrarily to the dope, the spidroins of the two spiders exhibit clear molecular differences in the fibers, although they share the same structural pattern. It may thus be suggested that the initial conformation in the dope is relatively unimportant with regards to the final structure of MA threads. The molecular characteristics of the dope (disordered chains involved in $31_{1}$-helical structures without intramolecular bonds) may however promote or be important for the efficient folding of the polypeptide chains into oriented $\beta$-sheets in the fiber, but some details of the final structure (accurate $\beta$-sheet content and level of orientation) may be modulated by the sequence and the spinning process.

The fact that the spidroin conformations of $N C$ and $A D$ exhibit disparities in the final state but not in the initial state suggests that sequence specificities are more extensively expressed in the solid than in the solution state. The intrinsic secondary structure propensity of NC and AD MA spidroins thus appear identical in solution. In particular, the GGX and GPGXX motifs, that are predominant in NC and $A D$ MA silk, respectively, seem to be conformationally equivalent in the dope. This may mostly be due to the chain flexibility in the aqueous environment (high conformational freedom), in particular to the prevalence of interactions between polypeptide chains and water (i.e., the absence of chain-chain interactions). After the spinning process, when the polypeptide chains are in close proximity and the intermolecular interactions maximized, the sequences seem to express their divergent secondary structures in the silk fiber.

\subsection{Molecular Orientation and $\beta$-Sheet Content Influence Silk Mechanical Properties}

The MA silks of the Nephila and Araneus genera differ in their tensile properties, the latter fibers being generally tougher and more extensible. Although mechanical differences have initially been observed in the dry state $[52,55,56,70]$, they appeared more recently not to be so clear when comparing $N C$ and $A D$ [13]. By contrast, distinctions in the mechanical behavior seem to be particularly marked in the wet (maximum supercontracted) state [13].

In recent years, deviation in the mechanical properties of the MA silk with species has been accounted for by the Pro content, for example by the fact that the $A D$ fiber is composed of two MaSp2-like proteins whereas that of NC is mainly made of MaSp1 [13,41,71]. The presence of Pro is expected to prevent the formation of regular secondary structure (mainly $\beta$-sheets), tight packing of the chains, and intermolecular H-bonding [13,39,41,42]. Contrarily, the Gly motifs, which are predominant in $N C$, would be more appropriate to form regular structures and an ordered organization [13]. 
The present data show that other structural parameters have to be taken into consideration when comparing MA silks. Molecular orientation and $\beta$-sheet content exhibit significant difference depending on the species. These two parameters obviously can strongly influence tensile properties. Their influence on MA silk properties is in line with findings regarding flagelliform silk. The large extensibility of this thread has long been related to the predominance of the GPGXX motif [72,73]. However, this silk also contains a small proportion of oriented $\beta$-sheets, which de facto includes this fiber into the archetypal MA silk family [74]. Thus, the increase in the breaking stress and breaking strain of this silk observed with different species seems to be related to higher $\beta$-sheet content and molecular alignment [74].

The amount of $\beta$-sheet of the NC and AD MA silk fibers can confidently be rationalized from the proportion of poly-Ala and GA motifs of the sequence, suggesting that the secondary structure content is in large part determined by the primary structure and is thus slightly influenced by the spinning process (although it is necessary to induce the conformational conversion towards $\beta$-sheets). The estimation of the $\beta$-sheet content by Raman spectromicroscopy and primary structure show that $\beta$-sheets are more abundant in NC than in AD MA silk. The lower $\beta$-sheet content of the AD MA silk, i.e., the higher proportion of amorphous phase, is likely to contribute to the higher extensibility of the $A D$ MA silk with respect to NC. It has been proposed that the presence of Pro (under the form of GPGXX motifs) may globally promote disordered structures, which in turn may make the MA fiber more flexible $[13,39,43,73]$. However, the present results indicate that the $\beta$-sheet content, and reversibly the global amount of disordered chains, is not affected by Pro residues. Pro may rather make the $A D$ amorphous phase more disordered than that of $N C$, which may in turn affect the tensile properties of these MA silks. Since the present results and conclusions have been obtained from only two spider species, they need to be generalized to a broader range of MA silks.

The Raman data also show that the level of molecular orientation of MA silk is higher for NC than for $A D$, which is in agreement with birefringence measurements [13]. This structural characteristic may also contribute to the fact that the fiber is more brittle for $N C$ than for $A D$. Since the MA silks investigated here have been reeled at the same speed, it may be questioned whether the different levels of orientation are determined by the spinning process. More precisely, the difference may arise from the different physicochemical composition, differences in the gland anatomy or, more probably, rheological properties of the dope. However, no data such as spidroin concentration in the dope actually supports such an assumption. A more likely hypothesis lies in the fact that the sequence may be at the origin of these structural differences. As a matter of fact, due to its pyrrolidine ring structure, Pro residues may limit the conformational flexibility of the chain, thus inhibiting chain extension and molecular alignment upon drawing.

\section{Materials and Methods}

Adult NC and $A D$ females were collected in Florida (USA) and Québec (Canada), respectively. They were raised in the laboratory at $24 \pm 2{ }^{\circ} \mathrm{C}$ and $58 \% \pm 5 \%$ relative humidity (RH) and fed with small crickets and $10 \% w / v$ glucose solution. For the analysis of liquid silk, the MA glands were extracted, deposited on glass slides or polystyrene petri dishes and immersed in a phosphate saline buffer. The epithelium was gently removed or pierced to expose the native liquid silk to the laser beam. Great care was taken to perturb minimally the silk material during the dissection procedure. In order to obtain fibers by forced reeling, spiders were anesthetized with $\mathrm{CO}_{2}$ and fixed on a support. The MA silk was then reeled on $1.3-\mathrm{cm}$ diameter test tubes from awaken spiders at $1 \mathrm{~cm} / \mathrm{s}$. MA silks were stored hidden from sunlight to avoid degradation.

About 5-cm long monofilaments were gently fixed on glass slides with one-sided tape at its extremities and at different locations along the fiber. The spectra were recorded at $22.0 \pm 0.5{ }^{\circ} \mathrm{C}$ and under 20\% $\pm 5 \%$ RH using a LabRam 800HR Raman spectrometer (Jobin Yvon Horiba, Villeneuve d'Ascq, France) coupled to an Olympus BX 30 motorized stage microscope. The 514.5-nm line of an argon-ion laser (Coherent, INNOVA 70C Series Ion Laser, Santa Clara, CA, USA) was used as 
excitation light. The laser beam was focused by a $100 \times$ objective (Numerical Aperture $(N A)=0.9$, Olympus, Richmond Hill, ON, Canada) generating an intensity of 3-5 $\mathrm{mW}$ at the sample. The confocal hole and the entrance slit of the monochromator were fixed at $400 \mu \mathrm{m}$ and $200 \mu \mathrm{m}$, respectively. A 600 lines/mm holographic grating was used to disperse the different wavenumbers of the samples on the one-inch open electrode Peltier-cooled CCD detector $(1024 \times 256$ pixels) (Andor Technologies, Belfast, Northern Ireland).

Spectra of the silk dope were recorded in the dry state as it has been shown that they are virtually identical to those obtained in the hydrated state [16]. Five spectra were recorded at different points on two distinctive dope samples. Orientation and secondary structure of the fibers were determined from the amide I band using linearly polarized light. A half-wave plate (Melles Griot, Carlsbad, CA, USA) was used to change the polarization of the incident light either perpendicular $(x)$ or parallel $(z)$ to the fiber axis (Figure S2). A polarizer was placed before the entrance slit of the monochromator to orient the polarization of the scattered light along the $\mathrm{x}$ or $\mathrm{z}$ direction. A broad-band quarter-wave plate was also used after the polarizer to eliminate the polarization dependence of the grating. Since the system works in a backscattering configuration, it allows the acquisitions of four independent polarized spectra (thereafter called a "series") with an acquisition time of $2 \times 30 \mathrm{~s}$ and identified as IXX, IXZ, IZZ, $\mathrm{I}_{Z X}$ (the first index corresponds to the incident light, the second to the scattered light). To ensure that the focus was constant through the acquisitions, i.e., that non-desired intensity variation occur during measurements, a second $I_{X X}$ spectrum was collected at the end of the series and compared with the first $\mathrm{I}_{X X}$ measurement. No sign of sample deterioration was observed under these experimental conditions.

Spectra treatments were all performed using GRAMS/AI 7.0 (ThermoGalactic, Salem, NH, USA). No smoothing was applied on the spectra. A cubic baseline was subtracted to correct the fluorescence background over the spectral range of $400-1800 \mathrm{~cm}^{-1}$. To take into account the polarization dependence of the instrument, correction factors were calculated from the totally depolarized band of liquid chloroform at $262 \mathrm{~cm}^{-1}$, which were then applied on the spectra of silk samples. For each series, the peak maximum of the amide I band IXX spectra was normalized to unity and the other polarized spectra normalized accordingly. The spectra were aligned along the wavenumbers axis using the tyrosine band at $1615 \mathrm{~cm}^{-1}$. For the present study we investigated three fibers, probed 1-3 points on each fiber and measured 1-3 series of polarized spectra on each point. The overall standard deviation on the measurement of the amide I intensity ratios is lower than 0.03 . Averaged polarized spectra were obtained from 12-14 series for each spider species over three different fibers.

For the determination of the secondary structure, orientation-insensitive spectra were calculated from a linear combination of the average polarized spectra [75]. The spectral decomposition of the amide I band was then carried out accordingly to the method previously described [59]. Briefly, a linear baseline was first subtracted in the amide I region $\left(1490-1750 \mathrm{~cm}^{-1}\right)$. The amide I band decomposition was carried out with five components located at 1640 (unordered structure), 1655 ( $3_{1}$-helix), 1669 ( $\beta$-sheet), 1682 (turn), and 1697 (turn) $\mathrm{cm}^{-1}$, respectively [59]. Mixed Lorentzian and Gaussian functions were used. Curve-fitting calculations were implemented using the initial band parameters (positions, widths and shapes) optimized previously for other MA silks with constraints on the variations of the parameters [59]. Band area of each component was divided by the total area of the amide I band to determine the structure content.

Molecular orientation was estimated qualitatively from the parameter $R^{\prime}$ defined as $R^{\prime}=1-\left(I_{X X} / I_{Z Z}\right)$. Positive and negative values of $R^{\prime}$ of the amide $I$ band indicate that the polypeptide chains are mainly parallel and perpendicular to the fiber axis, respectively. $R^{\prime}=0$ correspond to an isotropic sample. Molecular orientation was also assessed quantitatively in terms of order parameters $P_{2}$ and $P_{4}$ [76]. $P_{2}$ follows the same interpretation rules than $R^{\prime}$ but values are limited between -0.5 and 1 . The method to determine the order parameters $P_{2}$ and $P_{4}$ from polarized Raman measurements was first described by Bower (1972) [77]. It was extended to Raman spectromicroscopy (i.e., in backscattering configuration with four spectra) by Turrell and coworkers [78,79], and adapted to the amide I tensor (assuming a cylindrical symmetry) by Rousseau et al. [80]. This latter method, 
referred to as depolarization constant (DC) method by Richard-Lacroix et al. [67], requires the determination of the shape of the Raman tensor from an isotropic sample with the same chemical composition as the oriented sample, assuming that the depolarization ratio is identical for both samples. For silk, this ratio has previously been determined to be $0.21 \pm 0.01$ [80]. The details of the determination of $P_{2}$ and $P_{4}$ are determined from two polarized intensity ratios, noted $R_{1}=I_{\mathrm{ZX}} / I_{\mathrm{ZZ}}$ and $R_{2}=I_{X Z} / I_{X X}$, and are given elsewhere [80]. The order parameter values and the associated standard deviations were calculated from the mean intensity ratio values of each (three) fiber.

A variant of the DC method, called the most probable distribution (MPD) method, was proposed by Richard-Lacroix et al. [67]. This procedure eliminates the determination of the depolarization ratio and instead assumes that the orientation distribution is Gaussian. This assumption in turn provides a relationship between $P_{4}$ and $P_{2}$, which then allows their determination using the two ratios $R_{1}$ and $R_{2}$. Finally, the distribution of orientation was estimated by both methods by calculating the most probable distribution of orientation $\left(N_{\mathrm{mp}}(\theta)\right)$ from the values of $P_{2}$ and $P_{4}$ using the information entropy theory [81-84].

\section{Conclusions}

This work provides a structural comparison between the MA dope and fiber silk of the two widely studied spiders, $N C$ and $A D$. Quantitative values of the secondary structure contents and orientation of the MA spidroins have been determined. The $A D$ MA fiber exhibits lower structural and orientational orders compared to the NC thread. Such structural differences certainly contribute to the mechanical properties of these MA silks. Secondary structure (i.e., $\beta$-sheet content) of the fiber seems to be mainly driven by the amino acid sequence (poly-Ala content). It is proposed that Pro residues (partly) inhibit molecular alignment of $A D$ MA spidroins during the spinning process. The differences in the sequence of $N C$ and $A D$ spidroins do not result in distinctive conformation in the dope solution. This identical spidroin conformation suggests that it is not a decisive factor for the formation of specific fiber structure. Since differences in the mechanical properties of MA silk fibers are more obvious after supercontraction $[13,85]$, it appears necessary to examine the orientation level and secondary structure of these two silks in this state. Moreover, details regarding the effect of reeling speed on silk molecular structure may also be informative to better understand the effect of the spinning process on the orientation level.

Supplementary Materials: Supplementary materials can be found at www.mdpi.com/1422-0067/17/8/1353/s1.

Acknowledgments: This work is supported by grants from the Natural Sciences and Engineering Research Council of Canada (NSERC) and the Fonds de Recherche du Québec en Nature et Technologies (FRQNT). Justine Dionne acknowledges FRQNT and PROTEO for the award of graduate scholarships. The authors thank François Paquet-Mercier for his technical support with the Raman spectrometer, Simon Boudreault for his help with the MA gland dissection procedure and Philippe Bilodeau for his implication in the calculations of the order parameters and $N_{\mathrm{mp}}(\theta)$.

Author Contributions: The experiments were designed by Justine Dionne, Thierry Lefèvre and Michèle Auger. The experiments and the spectral treatments were conducted by Justine Dionne and Thierry Lefèvre. The interpretation of the data was performed by Justine Dionne and Thierry Lefèvre. The manuscript was written by Justine Dionne, Thierry Lefèvre and Michèle Auger.

Conflicts of Interest: The authors declare no conflict of interest.

\section{References}

1. Hardy, J.G.; Römer, L.M.; Scheibel, T.R. Polymeric materials based on silk proteins. Polymer 2008, 49, 4309-4327. [CrossRef]

2. Kundu, B.; Kurland, N.E.; Bano, S.; Patra, C.; Engel, F.B.; Yadavalli, V.K.; Kundu, S.C. Silk proteins for biomedical applications: Bioengineering perspectives. Prog. Polym. Sci. 2014, 39, 251-267. [CrossRef]

3. Lefèvre, T.; Auger, M. Spider silk as a blueprint for greener materials: A review. Int. Mater. Rev. 2016, 61, 127-153. [CrossRef] 
4. Lefèvre, T.; Auger, M. Spider silk inspired materials and sustainability: Perspective. Mater. Technol. 2016, 31, 384-399. [CrossRef]

5. Omenetto, F.G.; Kaplan, D.L. New opportunities for an ancient material. Science 2010, 329, 528-531. [CrossRef] [PubMed]

6. Warwicker, J.O. Comparative studies of fibroins. II. The crystal structures of various fibroins. J. Mol. Biol. 1960, 2, 350-362. [CrossRef]

7. Grubb, D.T.; Jelinski, L.W. Fiber morphology of spider silk: The effects of tensile deformation. Macromolecules 1997, 30, 2860-2867. [CrossRef]

8. Riekel, C.; Bräden, C.; Craig, C.L.; Ferrero, C.; Heidelbach, F.; Müller, M. Aspects of X-ray diffraction on single spider fibers. Int. J. Biol. Macromol. 1999, 24, 179-186. [CrossRef]

9. Termonia, Y. Molecular modeling of spider silk elasticity. Macromolecules 1994, 27, 7378-7381. [CrossRef]

10. Porter, D.; Vollrath, F.; Shao, Z. Predicting the mechanical properties of spider silk as a model nanostructured polymer. Eur. Phys. J. E 2005, 16, 199-206. [CrossRef] [PubMed]

11. Keten, S.; Buehler, M.J. Geometric confinement governs the rupture strength of H-bond assemblies at a critical length scale. Nanoletters 2008, 8, 743-748. [CrossRef] [PubMed]

12. Keten, S.; Xu, Z.; Ihle, B.; Buehler, M.J. Nanoconfinement controls stiffness, strength and mechanical toughness of $\beta$-sheet crystals in silk. Nat. Mater. 2010, 9, 359-367. [CrossRef] [PubMed]

13. Savage, K.N.; Gosline, J.M. The effect of proline on the network structure of major ampullate silks as inferred from their mechanical and optical properties. J. Exp. Biol. 2008, 211, 1937-1947. [CrossRef] [PubMed]

14. O’Brien, J.P.; Fahnestock, S.R.; Yves, T.; Gardner, K.H. Nylons from nature: Synthetic analogs to spider silk. Adv. Mater. 1998, 10, 1185-1195. [CrossRef]

15. Simmons, A.; Ray, E.; Jelinski, L.W. Solid-State ${ }^{13} \mathrm{C}$ NMR of Nephila clavipes dragline silk establishes structure and identity of crystalline regions. Macromolecules 1994, 27, 5235-5237. [CrossRef]

16. Lefèvre, T.; Paquet-Mercier, F.; Rioux-Dubé, J.-F.; Pézolet, M. Structure of silk by Raman spectromicroscopy: From the spinning glands to the fibers. Biopolymers 2012, 97, 322-336. [CrossRef] [PubMed]

17. Kummerlen, J.; van Beek, J.D.; Vollrath, F.; Meier, B.H. Local structure in spider dragline silk investigated by two-dimensional spin-diffusion nuclear magnetic resonance. Macromolecules 1996, 29, 2920-2928. [CrossRef]

18. Van Beek, J.D.; Hess, S.; Vollrath, F.; Meier, B.H. The molecular structure of spider dragline silk: Folding and orientation of the protein backbone. Proc. Natl. Acad. Sci. USA 2002, 99, 10266-10271. [CrossRef] [PubMed]

19. Valluzzi, R.; Szela, S.; Avtges, P.; Kirschner, D.; Kaplan, D. Methionine redox-controlled crystallization of biosynthetic silk spidroin. J. Phys. Chem. B 1999, 103, 11382-11392. [CrossRef]

20. Eles, P.T.; Michal, C.A. A DECODER NMR study of backbone orientation in Nephila clavipes dragline silk under varying strain and draw rate. Biomacromolecules 2004, 5, 661-665. [CrossRef] [PubMed]

21. Xu, M.; Lewis, R.V. Structure of a protein superfiber-Spider dragline silk. Proc. Natl. Acad. Sci. USA 1990, 87, 7120-7124. [CrossRef] [PubMed]

22. Hinnan, M.B.; Lewis, R.V. Isolation of a clone encoding a second dragline silk fibroin-Nephila clavipes dragline silk is a two-protein fiber. J. Biol. Chem. 1992, 267, 19320-19324.

23. Guerette, P.A.; Ginzinger, D.G.; Weber, B.H.F.; Gosline, J.M. Silk properties determined by gland-specific expression of a spider fibroin gene family. Science 1996, 272, 112-115. [CrossRef] [PubMed]

24. Andersen, S.O. Amino acid composition of spider silks. Comp. Biochem. Physiol. 1970, 35, 705-711. [CrossRef]

25. Work, R.W.; Young, C.T. The amino acid compositions of major and minor ampullate silks of certain orb-web-building spiders (Araneae, Araneidae). J. Arachnol. 1987, 15, 65-80.

26. Hayashi, C.Y.; Shipley, N.H.; Lewis, R.V. Hypotheses that correlate the sequence, structure, and mechanical properties of spider silk proteins. Int. J. Biol. Macromol. 1999, 24, 271-275. [CrossRef]

27. Simmons, A.H.; Michal, C.A.; Jelinski, L.W. Molecular orientation and two-component nature of the crystalline fraction of spider dragline silk. Science 1996, 271, 84-87. [CrossRef] [PubMed]

28. Hinman, M.B.; Jones, J.A.; Lewis, R.V. Synthetic spider silk: A modular fiber. Trends Biotechnol. 2000, 18, 374-379. [CrossRef]

29. Tokareva, O.; Jacobsen, M.; Buehler, M.; Wong, J.; Kaplan, D.L. Structure-function-property-design interplay in biopolymers: Spider silk. Acta Biomater. 2014, 10, 1612-1626. [CrossRef] [PubMed]

30. Askarieh, G.; Hedhammar, M.; Nordling, K.; Saenz, A.; Casals, C.; Rising, A.; Johansson, J.; Knight, S.D. Self-assembly of spider silk proteins is controlled by a pH-sensitive relay. Nature 2010, 465, 236-238. [CrossRef] [PubMed] 
31. Hagn, F.; Eisoldt, L.; Hardy, J.G.; Vendrely, C.; Coles, M.; Scheibel, T.; Kessler, H. A conserved spider silk domain acts as a molecular switch that controls fibre assembly. Nature 2010, 465, 239-242. [CrossRef] [PubMed]

32. Holland, C.; Terry, A.E.; Porter, D.; Vollrath, F. Comparing the rheology of native spider and silkwormspinning dope. Nat. Mater. 2006, 5, 870-874. [CrossRef] [PubMed]

33. Kojić, N.; Bico, J.; Clasen, C.; McKinley, G.H. Ex vivo rheology of spiders. J. Exp. Biol. 2006, 209, 4355-4362. [CrossRef] [PubMed]

34. Knight, D.P.; Vollrath, F. Liquid crystals and flow elongation in a spider's silk production line. Proc. R. Soc. Lond. B 1999, 266, 519-523. [CrossRef]

35. Vollrath, F.; Knight, D.P. Structure and function of the silk production pathway in the spider Nephila edulis. Int. J. Biol. Macromol. 1999, 24, 243-249. [CrossRef]

36. Vollrath, F.; Knight, D.P.; Hu, X.W. Silk production in a spider involves acid bath treatment. Proc. R. Soc. Lond. B 1998, 265, 817-820. [CrossRef]

37. Knight, D.P.; Vollrath, F. Changes in element composition along the spinning duct in a Nephila spider. Naturwissenschaften 2001, 88, 179-182. [CrossRef] [PubMed]

38. Andersson, M.; Chen, G.; Otikovs, M.; Landreh, M.; Nordling, K.; Kronqvist, N.; Westermark, P.; Joörnvall, H.; Knight, S.; Ridderstråle, Y.; et al. Carbonic anhydrase generates $\mathrm{CO}_{2}$ and $\mathrm{H}^{+}$that drive spider silk formation via opposite effects on the terminal domains. PLoS Biol. 2014, 12, e1001921. [CrossRef] [PubMed]

39. Liu, Y.; Sponner, A.; Porter, D.; Vollrath, F. Proline and processing of spider silks. Biomacromolecules 2008, 9, 116-121. [CrossRef] [PubMed]

40. Vollrath, F.; Porter, D. Spider silk as archetypal protein elastomer. Soft Matter 2006, 2, 377-385. [CrossRef]

41. Savage, K.N.; Gosline, J.M. The role of proline in the elastic mechanism of hydrated spider silks. J. Exp. Biol. 2008, 211, 1948-1957. [CrossRef] [PubMed]

42. Rauscher, S.; Baud, S.; Miao, M.; Keeley, F.W.; Pomès, R. Proline and glycine control protein self-organization into elastomeric or amyloid fibrils. Structure 2006, 14, 1667-1676. [CrossRef] [PubMed]

43. Blackledge, T.A.; Kuntner, M.; Marhabaie, M.; Leeper, T.C.; Agnarsson, I. Biomaterial evolution parallels behavioral innovation in the origin of orb-like spider webs. Sci. Rep. 2012, 2, 833. [CrossRef] [PubMed]

44. Gatesy, J.; Hayashi, C.; Motriuk, D.; Woods, J.; Lewis, R.V. Extreme diversity, conservation, and convergence of spider silk fibroin sequences. Science 2001, 291, 2603-2605. [CrossRef] [PubMed]

45. Shao, Z.; Vollrath, F. Surprising strength of silkworm silk. Nature 2002, 418, 741. [CrossRef] [PubMed]

46. Xia, X.-X.; Qiana, Z.-G.; Kib, C.S.; Park, Y.H.; Kaplan, D.; Lee, S.Y. Native-sized recombinant spider silk protein produced in metabolically engineered Escherichia coli results in a strong fiber. Proc. NatL. Acad. Sci. USA 2010, 107, 14059-14063. [CrossRef] [PubMed]

47. Marhabaie, M.; Leeper, T.C.; Blackledge, T.A. Protein Composition Correlates with the Mechanical Properties of Spider (Argiope trifasciata) Dragline Silk. Biomacromolecules 2014, 15, 20-29. [CrossRef] [PubMed]

48. Plaza, G.R.; Corsini, P.; Marsano, E.; Perez-Rigueiro, J.; Biancotto, L.; Elices, M.; Riekel, C.; Agullo-Rueda, F.; Gallardo, E.; Calleja, J.M.; et al. Old Silks Endowed with New Properties. Macromolecules 2009, 42, 8977-8982. [CrossRef]

49. Blamires, S.J.; Wu, C.L.; Blackledge, T.A.; Tso, I.M. Post-secretion processing influences spider silk performance. J. R. Soc. Interface 2012, 9, 2479-2487. [CrossRef] [PubMed]

50. Denny, M. The physical properties of spider's silk and their role in the design of orb-webs. J. Exp. Biol. 1976, 65, 483-506.

51. Madurga, R.; Blackledge, T.A.; Perea, B.; Plaza, G.R.; Riekel, C.; Burghammer, M.; Elices, M.; Guinea, G.; Perez-Rigueiro, J. Persistence and variation in microstructural design during the evolution of spider silk. Sci. Rep. 2015, 5. [CrossRef] [PubMed]

52. Stauffer, S.L.; Coguil, S.L.; Lewis, R.V. Comparison of physical properties of three silks from Nephila clavipes and Araneus diadematus. J. Arachnol. 1994, 22, 1-5.

53. Cunniff, P.M.; Fossey, S.A.; Auerbach, M.A.; Song, J.W.; Kaplan, D.L.; Adams, W.W.; Eby, R.K.; Mahoney, D.; Vezie, D.L. Mechanical and thermal properties of dragline silk from the spider Nephila clavipes. Polym. Adv. Technol. 1994, 5, 401-410. [CrossRef]

54. Gosline, J.M.; Guerette, P.A.; Ortlepp, C.S.; Savage, K.N. Mechanical design of spider silk: From fibroin sequence to mechanical function. J. Exp. Biol. 1999, 202, 3295-3303. [PubMed] 
55. Swanson, B.O.; Blackledge, T.A.; Beltrán, J.; Hayashi, C.Y. Variation in the material properties of spider dragline silk across species. Appl. Phys. A 2006, 82, 213-218. [CrossRef]

56. Swanson, B.O.; Blackledge, T.A.; Summers, A.P.; Hayashi, C.Y. Spider dragline silk: Correlated and mosaic evolution in high-performance biological materials. Evolution 2006, 60, 2539-2551. [CrossRef] [PubMed]

57. Swanson, B.O.; Blackledge, T.A.; Hayashi, C.Y. Spider capture silk: Performance implications of variation in an exeptional biomaterial. J. Exp. Biol. 2007, 307A, 654-666. [CrossRef] [PubMed]

58. Shao, Z.; Vollrath, F.; Sirichaisit, J.; Young, R.J. Analysis of spider silk in native and supercontracted states using Raman spectroscopy. Polymer 1999, 40, 2493-2500. [CrossRef]

59. Lefèvre, T.; Rousseau, M.-E.; Pézolet, M. Protein secondary structure and orientation in silk as revealed by Raman spectromicroscopy. Biophys. J. 2007, 92, 2885-2895. [CrossRef] [PubMed]

60. Xu, D.; Yarger, J.L.; Holland, G.P. Exploring the backbone dynamics of native spider silk proteins in Black Widow silk glands with solution-state NMR spectroscopy. Polymer 2014, 55, 3879-3885. [CrossRef]

61. Wait, S.C.; McNerney, J.C. Vibrational spectra and assignments for quinoline and isoquinoline. J. Mol. Spectrosc. 1970, 34, 56-77. [CrossRef]

62. Lefèvre, T.; Boudreault, S.; Cloutier, C.; Pézolet, M. Conformational and orientational transformation of silk proteins in the major ampullate gland of Nephila clavipes spiders. Biomacromolecules 2008, 9, 2399-2407. [CrossRef] [PubMed]

63. Rousseau, M.-E.; Lefèvre, T.; Pézolet, M. Conformation and orientation of proteins in various types of silk fibers produced by Nephila clavipes spiders. Biomacromolecules 2009, 10, 2945-2953. [CrossRef] [PubMed]

64. Denny, M.W. Silks-Their properties and functions. In The Mechanical Properties of Biological Materials; Society for Experimental Biology, Ed.; Cambridge University Press: Cambridge, UK, 1980; Volume XXXIV, pp. 246-272.

65. Craig, C.L. Evolution of arthropod silks. Annu. Rev. Entomol. 1997, 42, 231-267. [CrossRef] [PubMed]

66. Plaza, G.R.; Perez-Rigueiro, J.; Riekel, C.; Perea, G.B.; Agullo-Rueda, F.; Burghammer, M.; Guinea, G.V.; Elices, M. Relationship between microstructure and mechanical properties in spider silk fibers: Identification of two regimes in the microstructural changes. Soft Matter 2012, 8, 6015-6026. [CrossRef]

67. Richard-Lacroix, M.; Pellerin, C. Novel method for quantifying molecular orientation by polarized raman spectroscopy: A comparative simulations study. Appl. Spectrosc. 2013, 67, 409-419. [CrossRef] [PubMed]

68. Jelinski, L.W.; Blye, A.; Liivak, O.; Michal, C.; LaVerde, G.; Seidel, A.; Shah, N.; Yang, Z. Orientation, structure, wet-spinning, and molecular basis for supercontraction of spider dragline silk. Int. J. Biol. Macromol. 1999, 24, 197-201. [CrossRef]

69. Lefèvre, T.; Leclerc, J.; Rioux-Dubé, J.-F.; Buffeteau, T.; Paquin, M.-C.; Rousseau, M.-E.; Cloutier, I.; Auger, M.; Gagné, S.M.; Boudreault, S.; et al. Conformation of spider silk proteins in situ in the intact major ampullate gland and in solution. Biomacromolecules 2007, 8, 2342-2344. [CrossRef] [PubMed]

70. Kohler, T.; Vollrath, F. Thread biomechanics in the two orb-weaving spiders Araneus diadematus (Araneae, Araneidae) and Uloborus walckenaerius (Araneae, Uloboridae). J. Exp. Zool. 1995, 271, 1-17. [CrossRef]

71. Sensenig, A.; Agnarsson, I.; Blackledge, T.A. Behavioural and biomaterial coevolution in spider orb webs. J. Evol. Biol. 2010, 23, 1839-1856. [CrossRef] [PubMed]

72. Hayashi, C.Y.; Lewis, R.V. Molecular architecture and evolution of a modular spider silk protein gene. Science 2000, 287, 1477-1479. [CrossRef] [PubMed]

73. Hayashi, C.Y.; Lewis, R.V. Evidence from flagelliform silk cDNA for the structural basis of elasticity and modular nature of spider silks. J. Biol. Mol. 1998, 275, 773-784. [CrossRef] [PubMed]

74. Lefèvre, T.; Pézolet, M. Unexpected $\beta$-sheets and molecular orientation in flagelliform spider silk as revealed by Raman spectromicroscopy. Soft Matter 2012, 8, 6350-6357. [CrossRef]

75. Lefevre, T.; Rousseau, M.E.; Pézolet, M. Orientation-insensitive spectra for Raman microspectroscopy. Appl. Spectrosc. 2006, 60, 841-846. [CrossRef] [PubMed]

76. Lefèvre, T.; Pellerin, C.; Pézolet, M. Characterization of molecular orientation. In Molecular Characterization and Analysis of Polymers; Chalmers, J., Meier, R.J., Eds.; Elsevier: Amsterdam, The Newtherlands, 2008; Volume 53, pp. 295-335.

77. Bower, D.I. Investigation of molecular orientation distributions by polarized Raman scattering and polarized fluorescence. J. Polym. Sci. 1972, 10, 2135-2153. [CrossRef]

78. Turrell, G. Analysis of polarization measurements in Raman microspectroscopy. J. Raman Spectrosc. 1984, 15, 103-108. [CrossRef] 
79. Turrell, G. Raman sampling. In Practical Raman Spectroscopy; Gardiner, D.J., Graves, P.R., Eds.; Spriner-Verlag: Berlin, Germany, 1989; pp. 13-54.

80. Rousseau, M.-E.; Lefèvre, T.; Beaulieu, L.; Asakura, T.; Pézolet, M. Study of protein conformation and orientation in silkworm and spider silk fibers using Raman microspectroscopy. Biomacromolecules 2004, 5, 2247-2257. [CrossRef] [PubMed]

81. Lagugné-Labarthet, F.; Buffeteau, T.; Sourisseau, C. Orientation distribution functions in uniaxial systems centered perpendicularly to a constraint direction. Appl. Spectrosc. 2000, 54, 699-705. [CrossRef]

82. Pottel, H.; Herreman, W.; ven der Meer, B.W.; Ameloot, M. On the significance of the fourth-rank orientational order parameter of fluorophores in membranes. Chem. Phys. 1986, 102, 37-44. [CrossRef]

83. Berne, B.J.; Pechukas, P.; Harp, G.D. Molecular reorientation in liquids and gases. J. Chem. Phys. 1968, 49, 3125-3129. [CrossRef]

84. Bower, D.I. Orientation distribution functions for uniaxially oriented polymers. J. Polym. Sci. 1981, 19, 93-107. [CrossRef]

85. Elices, M.; Plaza, G.R.; Arnedo, M.A.; Pérez-Rigueiro, J.; Torres, F.G.; Guinea, G.V. Mechanical behavior of silk during the evolution of orb-web spinning spiders. Biomacromolecules 2009, 10, 1904-1910. [CrossRef] [PubMed]

(C) 2016 by the authors; licensee MDPI, Basel, Switzerland. This article is an open access article distributed under the terms and conditions of the Creative Commons Attribution (CC-BY) license (http://creativecommons.org/licenses/by/4.0/). 